Review

\title{
Infectious Diseases Are Analogous With Cancer. Hypothesis And Implica- tions
}

\section{Daniel Benharroch ${ }^{\bowtie}$, Lidia Osyntsov}

Department of Pathology, Soroka University Medical Center and Faculty of Health Sciences, Ben-Gurion University of the Negev, Beer-Sheva, Israel.

Corresponding author: Daniel Benharroch, M.D., Department of Pathology, Soroka University Medical Center, P.O.Box 151, Beer-Sheva 84101, Israel. Tel. 972-8-6400920. e-mail: benaroch@bgu.ac.il

(C) Ivyspring International Publisher. This is an open-access article distributed under the terms of the Creative Commons License (http://creativecommons.org/ licenses/by-nc-nd/3.0/). Reproduction is permitted for personal, noncommercial use, provided that the article is in whole, unmodified, and properly cited.

Received: 2011.12.18; Accepted: 2012.03.02; Published: 2012.03.06

\begin{abstract}
We propose to disclose first degree analogous features between cancer and infectious diseases and to find out whether these similarities are superficial and negligible, due to the use of the same bodily pathways by the two categories of disease or if they represent significantly parallel characteristics. We have found several primary analogous features, predominantly regarding pathways of spread, but to some extent also concerning the interaction with the immune system. Some of the implications to our hypothesis are probably available in the recent literature, at the experimental or clinical levels. For example endostatin, an angiogenic inhibitor has been used to prevent promotion of metastasis in cancer and to reduce granulomas formation in schistosomiasis. An ECFR antagonist employed to restrain bronchial vessels proliferation in pseudomonas infection, has also been used for the treatment of lung cancer.
\end{abstract}

Key words: cancer; infectious disease; analogy; spread; immunity.

\section{Introduction}

Cancer and infectious diseases are totally distinct categories of ailments. But at times they may present with similar symptoms and signs [1, 2]. They are however treated with different modalities of therapy. Usually, infectious diseases do not carry the gloomy outlook of malignant tumors, although an infection may be fatal or develop at the end of treatment of a cancer.

When searching for the similarities, they seem to be found superficially in several aspects of the two categories of illnesses. Prominent among these are parallel immediate means of spread [3, 4], some aspects of the role of immunity [5] and the characteristics of terminal events occurring in these diseases.

We have reviewed the analogous features of these two categories of diseases, in an attempt to find out whether they are absent or negligible, if they present with similar mechanisms or if they possess common properties. We have attempted to refrain from mentioning strictly different features which represent the usual occurrence.

\section{Pathogenic agents and genes}

a priori, one should not be able to find any similarity between genes involved in carcinogenesis and microbes. The analogy, if any, may be limited to the fact that both oncogenes and pathogenic microorganisms cause morbidity and mortality, though in markedly different ways. However, oncogene activation is inhibited by that of tumor suppressor genes, in a way which reminds superficially of the normal flora which checks the growth of pathogens at several body 
sites $[6,7]$. When tumor suppressor genes are overwhelmed by a mutation (deletion), the burst of tumor growth may evoke an association with the infectious morbidity that occurs when the normal flora is destroyed by wide spectrum antibiotics [7]. Tumor suppressor genes, by promoting growth inhibition, remind in a way of the normal flora, which by proliferating on the skin, gastrointestinal tract and vagina, prevents the outgrowth of pathogenic microorganisms.

A further parallel feature is that of oncogenic viruses and bacteria which promote an infectious disease on the one hand and are capable of causing cancer on the other hand, following a long latent period $[3,8]$.

\section{Spread and dissemination}

Mechanisms of spread at the molecular level are as different as possible in the two categories of disease discussed. Nevertheless, the primary aspects of the modalities of spread seen in malignant tumors parallel almost fully those described in infectious diseases $[3,4,9]$.

Local invasion at the site of the primary tumor, in continuity, is an important property of malignancy, as it is necessary for the tumor to reach tissue planes that will promote further dissemination [4]. In infections, proliferation and spread at the portal of entry may at times represent the only mode of dissemination of the microbe. But often, it is followed in cancer as well as in infectious diseases by one or more of the mechanisms of spread: lymphatic spread, hematogenous dissemination, spread through body cavities as well as along nerves $[3,4]$. These pathways support the dissemination of both infectious agents and tumor cells, even though the mechanisms involved are different.

The various modalities of spread lend to the tumor or the infection a dimension of increased illness severity [3, 10]. Thus, in cancer, local invasiveness, usually followed by metastasis, will indicate a low or nil potential for cure [4]. Hematogenous spread of a microbe, culminating in septicemia, will carry out a severe morbidity and in the case of Gram negative bacilli a very high mortality [11].

The above description is very suggestive of an analogy based on the use by both categories of diseases of the same bodily pathways. And in fact, the morphology, together with the activation of similar adhesion molecules, or the epithelial mesenchymal transition, may explain the resemblance of the spreading mechanisms. The similarity is indeed high, pending our restriction to the primary features of spread and attempting not to bring out the marked difference between the two sorts of disease.

\section{Role of immunity}

The strongest evidence for the existence of "immune surveillance" is the increased frequency of cancer in immunosuppressed patients. However, these patients suffer predominantly from lymphomas [11].

Patients with immune suppression are at a high risk of developing opportunistic infections [12]. However most cancer patients are immunocompetent [12] and most infectious diseases arise in basically healthy individuals and are caused by common virulent microbes [13]. Thus, tumor cells have to set up mechanisms to evade the immune system [14, 15]. Similarly, infectious agents have to overcome the body barriers, as well as the immune mechanisms [14].

Both categories of diseases may have in common loss or reduced expression of class I MHC molecules, thus escaping attacks by cytotoxic T-cells [16]. We may find antigen masking with both tumor cells and infection that will render the cell or pathogen inaccessible to the immune system (Clostridium difficile, salmonella typhi). Both may use antigen variation: cancer cells will outgrow selectively antigen negative variants to prevent access to immune mechanisms [17].

Thus there are a few similarities in the way these two types of disease manipulate the immune system to their advantage. However, the immune system has the capacity to fight numerous infectious agents and cancer cells using a vast array of mechanisms. But again, the emphasis in this review is on the common denominators and not on the differences between the types of disease.

\section{Treatment and complications}

Chemotherapy, in its most simple sense, is the treatment of a disease by chemicals, especially for killing microorganisms or cancerous cells. This term is now used predominantly in oncology for the treatment of malignant diseases [18].

At times, a cancer develops during the process of an infectious disease. Most prominent in this context are neoplasms occurring at some point in relation with a viral disease $[8,19]$.

Infection by HTLV-1, a retrovirus, may lead, after some delay, to adult T-cell leukemia/lymphoma [20].

The other oncogenic viruses are mainly DNA viruses and include the human papillomavirus, the cause of genital warts and of cervical, anal and oropharyngeal cancers $[8,21,22]$. Hepatitis $B$ virus and 
hepatitis C virus (a RNA virus), are considered the etiological factors of most hepatocellular cancers in man $[19,23,24]$. Epstein-Barr virus has been associated with diffuse large B-cell lymphoma, mainly in relation with immune suppression; with endemic Burkitt lymphoma and with a fraction of the sporadic form of this tumor; with a proportion of Hodgkin lymphoma; with nasopharyngeal carcinoma and with a small group of gastric cancer [25-27]. Kaposi sarcoma-related herpes virus (HHV-8) has been associated with Kaposi sarcoma, multicentric Castleman's disease and with body cavities-related large B-cell lymphoma [28].

In most oncogenic viral-related neoplasms a chronic inflammation precedes the malignant transformation and represents a chronic persistent viral infection. When examining the association between chronic inflammation and malignant transformation, these persistent viral infections have been listed together with celiac disease, Crohn's disease as well as autoimmune diseases, as conditions that may precede the development of malignant diseases.

In the last decades, a few bacterial infections have demonstrated a link with cancer. The most firmly established relationship is between Helicobacter pylori and low-grade mucosa associated lymphoid tissue (MALT) lymphoma, as well as with gastric carcinoma $[29,30]$. An association between low-grade MALT-oma of the skin and infection by Borrelia burgdorferi has been shown, at best, to be limited to European countries [31, 32]. Lately, low-grade MALT-lymphoma of the ocular adnexae (eyelid, conjunctiva, orbit, lacrimal tracts and glands) has been tentatively connected with infection by Chlamydophilia psittaci [33]. Thus, a microbial infection may at times also deteriorate into a malignant tumor.

On the other hand, cancer patients often develop an opportunistic infection that may be fatal. This event may be a complication of the neoplasm or be indirectly due to immune suppression that follows cancer therapy. Thus, the health of a cancer patient may deteriorate due to an opportunistic, perhaps fatal infection. This analogy between malignant tumors and infection may be superficial, but it however becomes more significant as the transformation leads to death.

Tumor progression will lead as a rule to tumor heterogeneity. The appearance of neoplastic subclones will promote tumor aggressiveness, invasiveness and increased metastatic potential which may anticipate the patient death [34].

Microbial infections, if partially treated or developing in a weakened or immunosuppressed patient, will tend to become persistent. The microbes may acquire additional factors of invasiveness. The infectious disease will then become more aggressive, with increased potential for septicemia and patient death [5].

In both branches of the analogy the agent (tumor cell or microbe) is transformed into a more aggressive player in the development of the disease. This lends the parallel features of the cancer and infection a higher degree of significance.

\section{Miscellaneous}

The peculiar mother-fetus relationship has been likened with the association host-cancer. Similarly to the fetus, the tumor cells may hide the expression of the MHC type I molecules and refrain from expressing foreign (non-self) antigens [35]. An analogous behavior, though not identical, may occur with infectious agents. Patients with typhoid fever may develop a carrier state following the acute infection. In this condition, the Salmonella typhi will grow unharmed in the gallbladder or urinary bladder and will be shed occasionally to contaminate innocent individuals. A hydatid cyst is a further example of a similar occurrence.

However rare and mainly limited to melanoma, transplacental metastasis has been described [35-37]. Transplacental infections transferred from mother to fetus, are probably more frequent [35].

Male circumcision is presented to highlight a therapeutic aspect of a possible analogy between the two groups of ailments. Circumcision is carried out for traditional reasons, the significance of which is unclear, but may be related to hygiene. This traditional intervention mostly resolves two problems, infectious illnesses, which are now known to include prevention of HPV contamination by the male and directly, reduction of the rate of penile squamous cell carcinoma.

\section{Conclusions}

We have described several analogies between cancer and infectious diseases, some stronger, others less so. The more marked similarities concern the mechanism of spread and dissemination, and the association with the immune system. This comes as no surprise as both tumor cells and infectious agents are considered at some point as "foreign" (non-self) invaders.

Consequently, and restricting our discussion to the most primary features of the comparison, we offer our hypothesis that cancer and infectious diseases have some descriptive and perhaps also some "mechanistic" features in common. If the hypothesis has a sound basis, it may imply that the two catego- 
ries of disease have several aspects in common, perhaps including therapeutic and preventing traits. In fact, interferons have been used as a treatment of both, infectious diseases and cancer, most strikingly for $\mathrm{HBV}$ infection and for the prevention of liver cancer related with $\mathrm{HBV}$.

Endostatin, an anti-angiogenic factor has been used to reduce the volume of granulomas in schistosomiasis. This agent has also been employed for the inhibition of neoangiogenesis of cancer and against the subsequent promotion of metastasis [38].

Pseudomonas aeruginosa induces VEGF synthesis, thus causing bronchial vessels proliferation. The effect due to this Gram-negative bacillus has been prevented by an EGFR-antagonist [39], which may play a role in the treatment of non-small cell lung cancer.

\section{Acknowledgement}

This study was supported in part by Kibbutz Sde-Boker, Israel. Many thanks are sent to the Department of Desert Ecology, Midreshet Ben-Gurion Institutes, Ben-Gurion University of the Negev, Israel, for their hospitality.

\section{Conflict of Interest}

The authors have declared that no conflict of interest exists.

\section{References}

1. Paterson R, Paterson E: Hodgkin's disease. Brit Med J; 1954;2: 1315-1318.

2. Petersdorf RG, Larson E: FUO revisited. Trans Am Clin Climatol Assoc; 1983, 94: 44-55.

3. Mims CA, Nash A, Stephen J. The spread of microbes through the body. Mims' pathogenesis of infectious diseases; 5 th edition. San Diego: Academic Press; 2001: 119-148.

4. Stricker TP, Kumar V. Neoplasia. In: Kumar V, et al, eds. Robbins and Cotran' Pathologic basis of disease; 8th edition. China: Saunders; 2010: 268-270; 286-295; 298-301; 316-320.

5. Mims CA, Nash A, Stephen J. The immune response to infection. Mims' pathogenesis of infectious diseases; 5th edition. San Diego: Academic Press; 2001:149-215.

6. Mims CA, Nash A, Stephen J. Attachment to and entry of microorganisms into the body. Mims' pathogenesis of infectious diseases; 5th edition. San Diego: Academic Press; 2001: 19-20; 25-30.

7. Stewardson AJ, Huttner B, Harbarth S. At least it won't hurt: the personal risk of antibiotic exposure. Curr Opin Pharmacol; 2011;11: 446-452.

8. Boccardo E, Lepique AP, Villa LL. The role of inflammation in HPV carcinogenesis. Carcinogenesis; 2010;31: 1905-1912.

9. Banys M, Gruber I, Krawczyk N, Becker S, Kurth L, Wallweiner D, Jakubowska J, Hoffman J, Rothmund R, Staebber A, Fehm T. Hematogenous and lymphatic tumor cell dissemination may be detected in patients diagnosed with ductal carcinoma in situ of the breast. Breast Cancer Res Treat; 2011; [Epub ahead of print].

10. Petz JO, Stojandinovic A, Nissan A, Hohenberger W, Esquivel J. Evaluation of a peritoneal surface disease severity score in pa- tients with colon cancer with peritoneal carcinomatosis. J Surg Oncol; 2009;99: 9-15.

11. Mitchell RN. Hemodynamic disorders, thromboembolic disease, and shock. In: Kumar V, et al, eds. Robbins and Cotran's Pathologic basis of disease; 8th edition. China: Saunders; 2010:129-132; 319-320.

12. Miceli MH, Diaz JA, Lee SA. Emerging opportunistic yeast infections. Lancet Infect Dis; 2010;11: 142-151.

13. McAdam AJ, Sharpe AH. Infectious diseases. In: Kumar V, et al, eds. Robbins and Cotran's Pathologic basis of disease; 8th edition. China: Saunders; 2010: 346-347.

14. Drygiannakis I, Ernst PB, Lowe D, Glomski IJ. Immunological alterations mediated during host-microbial interactions. Immunol Res; 2011;50: 69-77.

15. Dubovsky JA, Villagra A, Powers JJ, Wang HW, Pinilla-Ibarz J, Sotomayor EM. Circumventing immune tolerance through epigenetic modification. Curr Pharm Des; 2010;16: 268-276.

16. Aptsiauri N, Cabrera T, Mendez R, Garcia-Lora A, Ruiz-Cabello F, Garrido F. Role of altered expression of HLA class I molecules in cancer progression. Adv Exp Med Biol; 2007;601: 123-131.

17. Boyton RJ, Altmann DM. Natural killer cells, killer Immunoglobulin-like receptors and human leukocyte antigen class I in disease. Clin Exp Immunol; 2007;149: 1-8.

18. Andrade RJ, Tulkens PM. Hepatic safety of antibiotics used in primary care. J Antimicrobial Chemother; 2011;66: 1431-1446.

19. Lin C-L, Kao J-H. The clinical implications of hepatitis B virus genotype: recent advances. J Gastroenterol Hepatol; 2011;26(Suppl 1): 123-130.

20. Taylor GP, Matsuoka M. Natural history of adult T-cell leukemia/lymphoma and approaches to therapy. Oncogene; 2005;24: 6047-6057.

21. Longworth M, Laimins LA. Pathogenesis of human papillomaviruses in differentiating epithelia. Microbiol Molec Biol Rev; 2004;68: 362-372.

22. Bodily J, Laimins LA. Persistence of human papillomavirus infection: keys to malignant progression. Trends Microbiol; 2011;19: 34-39.

23. Nguyen VTT, Law MG, Dore GJ. Hepatitis B-related hepatocellular carcinoma: epidemiological characteristics and disease burden. J Viral Hepatitis; 2009;16: 453-463.

24. McGivern DR, Lemon SM. Virus-specific mechanisms of carcinogenesis in hepatitis C virus-associated liver cancer. Oncogene; 2011;30: 1969-1983.

25. Saha A, Roberston ES. Epstein-Barr virus-associated B-cell lymphomas: pathogenesis and clinical outcomes. Clin Cancer Res; 2011;17: 3056-3063.

26. Shao J-Y, Ernberg I, Biberfeld P, Heiden T, Zeng Y-X, Hu L-F. Epstein-Barr virus LMP1 status in relation to apoptosis, p53 expression and leukocyte infiltration in nasopharyngeal carcinoma. Anticancer Res; 2004;24: 2309-2318.

27. Han van Krieken J. New developments in the pathology of malignant lymphoma. J Hematopathol; 2009;2: 50-61.

28. Cronin DM, Warnke RA. Castleman disease: an update on classification and the spectrum of associated lesions. Adv Anat Pathol; 2009;16: 236-246.

29. Zullo A, Hassan C, Andiani A, Cristofari F, De Francesco V, Ierardi E, Tomao S, Morini S, Vaira D. Eradication therapy for Helicobacter pylori in patients with gastric MALT lymphoma. Am J Gastroenterol; 2009;104: 1932-1937.

30. Bornshein J, Rokkas T, Selgrad M, Malfertheiner P. Helicobacter pylori and clinical aspects of gastric cancer. Helicobacter; 2009; 14 (Suppl 1): 41-45.

31. Colli C, Leinweber B, Mullegger R, Chott A, Kerl H, Cerroni I. Borrelia burgdorferi- associated lymphocytoma cutis: clinicopathologic, immunophenotype and molecular study of 106 cases. J Cutan Pathol; 2004;31: 232-240. 
32. Takino H, Li C, Hu S, Kuo TT, Geissinger E, Muller-Hermelink HK, Kim B, Swerdlow SH, Inagaki H. Primary cutaneous marginal zone B-cell lymphoma: a molecular study of cases from Asia, Germany, and the United States. Modern Pathol; 2008;21: 1517-1528.

33. Ferreri AJM, Ernberg I, Copie-Bergman C. Infectious agents and lymphoma development: molecular and clinical aspects. J Intern Med; 2009;265: 421-438.

34. Stricker TP, Kumar V. Essential alterations for malignant transformation. In: Kumar V, et al, eds. Robbins and Cotran's Pathologic basis of disease; 8th edition. China: Saunders; 2010:278-279.

35. Robbins JR, Skrzypczynska KM, Zeldovich VP, Kapidzic M, Bakardjiev AI. Placental syncytiotrophoblast constitutes a major barrier to vertical transmission of Listeria monocytogenes. PLoS Pathog; 2010; 22: e1000732.

36. Altman JF, Lowe L, Redman B, Esper P, Schwartz JL, Johnson TM, Haefner HK. Placental metastasis of maternal melanoma. J Am Acad Dermatol; 2003;49: 1150-1154.

37. Folk JJ, Curioca J, Nosovitch JT Jr, Silverman RK. Poorly differentiated large cell adenocarcinoma of the lung metastatic to the placenta. J Rep Med; 2004;49: 395-397.

38. Shariati F, Perez-Arellaro JL, Carranza C, Lopez-Alban J, Vincente B, Arefi M, Muro A. Evaluation of the role of angiogenic factors in the pathogenesis of schistosomiasis. Exp Parasitol; 2011;128:44-49.

39. Martin C, Thevenot G, Danel S, Chapron J, Tazi A, Macey J, Dusser DJ, Fajac I, Burgel PR. Pseudomonas aeruginosa induces vascular endothelial growth factor synthesis in airway epithelium in vitro and in vivo. Eur Respir J; 2011;38: 939-946. 